\title{
The moulded double-rocker plaster shoe in the field treatment of plantar ulcer
}

\author{
B JOSEPH, S JOSHUA \& E P FRITSCHI \\ Schieffelin Leprosy Research \& Training Centre, Karigiri, North \\ Arcot District, Tamil Nadu, India. Pin: 632106. \\ Received for publication 14 April 1982
}

\begin{abstract}
Summary The present study has shown that the moulded double rocker plaster shoe offers a very feasible method of treatment of the simple plantar ulcer under field conditions. It is effective, inexpensive, socially acceptable and it can be applied, and the patient sent home, on the same day. There are no significant complications which have been noted either during or subsequent to this trial.
\end{abstract}

\section{Introduction}

A simple plantar ulcer is defined as one that involves only the skin and subcutaneous tissue. ${ }^{1}$ It has a visible floor, no deep sinus, no local warmth, no oedema or redness and minimal discharge. If very chronic it may show clean punched-out edges.

This study was carried out to determine the usefulness of the moulded double rocker plaster shoe (MDRP shoe), as an outpatient ambulatory treatment of simple plantar ulcers in leprosy patients reporting to the Outpatient Department of the Schieffelin Leprosy Research \& Training Centre, Karigiri.

Initially the plan had been to compare this smaller plaster shoe with the standard below knee plaster cast, which has for many years proved its worth in the treatment of these ulcers. However, it was found impossible to implement the predetermined random allocation, because the patients refused to have the standard plaster boot applied unless they were admitted. The present design of the study therefore is based on the fact that, in most village clinics, the normal treatment of simple ulcers is to give the patient some advice, where possible a sandal and some dressing materials for home care.

The following questions were asked:

1 Is the MDRP shoe effective? 
2 Is it socially acceptable and economically feasible in the field?

3 Are there any complications?

\section{Materials and methods}

\section{Case selection:}

Forty-two patients with simple ulcers were selected from the Outpatient Department of the Schieffelin Centre. Those with drop feet were excluded from the trial. Diabetes mellitus was ruled out in all the patients. All the patients were examined clinically and classified. They were fully documented with X-rays, photographs, Harris mat foot prints, ${ }^{2,3}$ full sensory and motor assessment and ulcer measurements.

They were assigned to one of two groups in accordance with a predetermined randomized serial order with 21 patients in each of the two groups. The first group had MDRP shoes applied over the magnesium sulphate glycerine (MSG) dressing. The other group were given MSG dressings for home use, and a pair of standard Y-strap sandals with microcellular sole and an arch support and metatarsal pad. The same type of sandals were issued to the first group to be worn on the good foot initially, and on both after the healing of the ulcer.

All the patients were reviewed after 4 weeks, that being the normal interval between clinic attendances. Where the ulcer did not heal in the first 4 weeks it was re-applied and again reviewed after a 4-week interval.

Both groups were given intensive health education in the care of their feet and were taught the technique of foot soaking, scraping, oil massage and daily foot inspection, and how to deal with pre-ulcerative conditions such as fissures, corns, callouses, blisters and haematomata.

At the first and subsequent visits, all were examined carefully for signs of inflammation such as oedema, warmth, redness, regional lymphadenitis and any change in the ulcer category or size. Repeat X-rays, Harris-mat impressions and photographs were taken. All patients had another session of health education.

\section{Application of the moulded double rocker plaster shoe ${ }^{1}$}

Materials required: one roll of gauze bandage; two rolls of plaster of Paris (POP) bandage (home-made); and one wooden footpiece with two rockers attached.

A sterile mag. sulph. glycerine acriflavine dressing was applied over the ulcer. A gauze bandage was put on over the entire foot up to the ankle joint, care being taken to apply small gauze pads between the toes. 


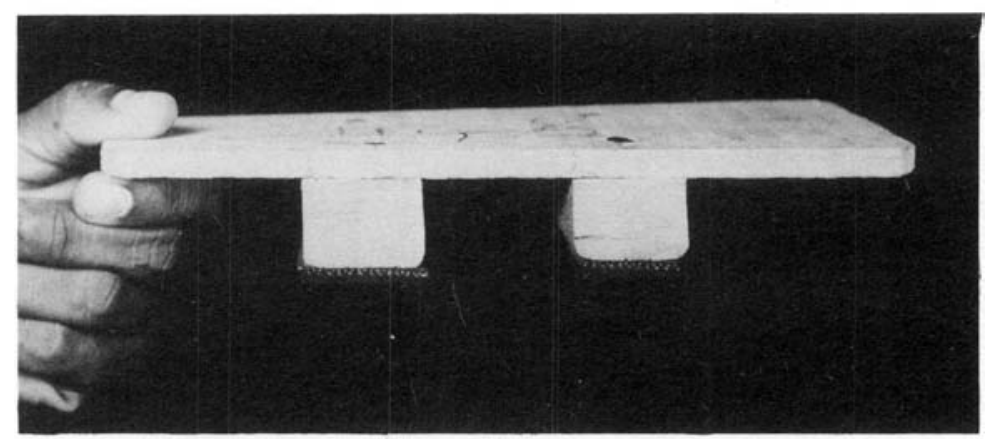

Figure 1. The double rocker used for the plaster shoe. Note the protective rubber layer under the rockers.

One layer of POP bandage is applied over the whole foot up to the ankle level (below the malleoli), and then the wooden footpiece with rockers is held under the sole. The medial and lateral arches of the foot are filled in with POP bandages. The second roll of POP bandage is then applied over the whole foot including the toes, holding the wooden footpiece in place.

Four hours after application the patient was allowed to walk with full weight bearing on the plaster shoe. This period was possible because the patients selected for this trial had their plaster shoes applied in the Outpatients Department. One hour for drying has been tried in the field and found adequate.

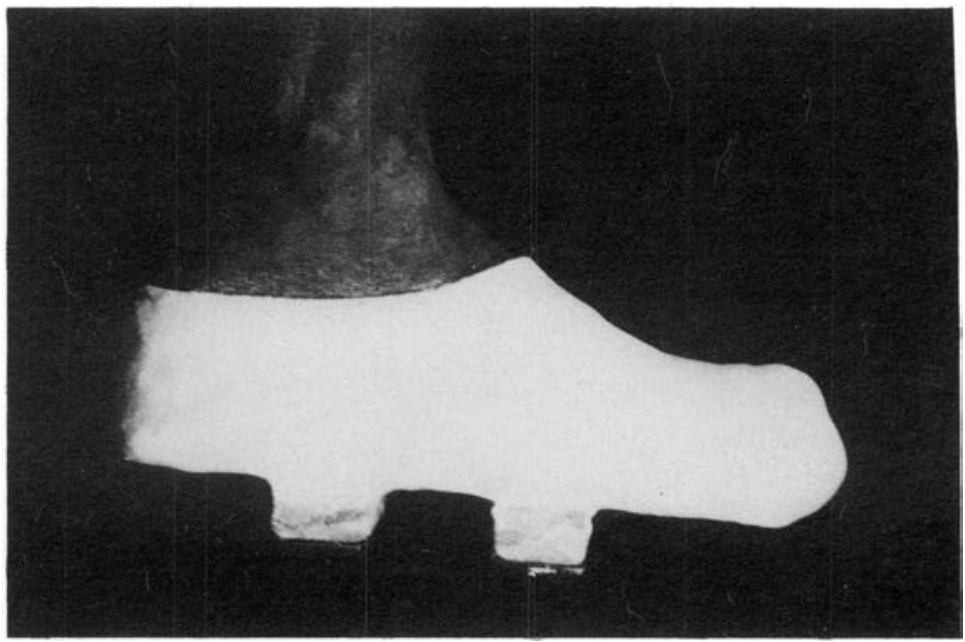

Figure 2. A finished shoe on the foot. 
Table 1 shows a comparison of the features of the two groups. It will be seen that the groups were satisfactorily matched in age and sex, and only in classification were there some major differences.

Table 2 shows a comparison of the ulcers in terms of site and size. It can be seen that here also the two groups were well matched.

Table 3 shows the results of the trial at the second visit, and it can be seen that $65 \%$ of the ulcers in the trial group had healed in 4 weeks in comparison with $12.5 \%$ in the control group.
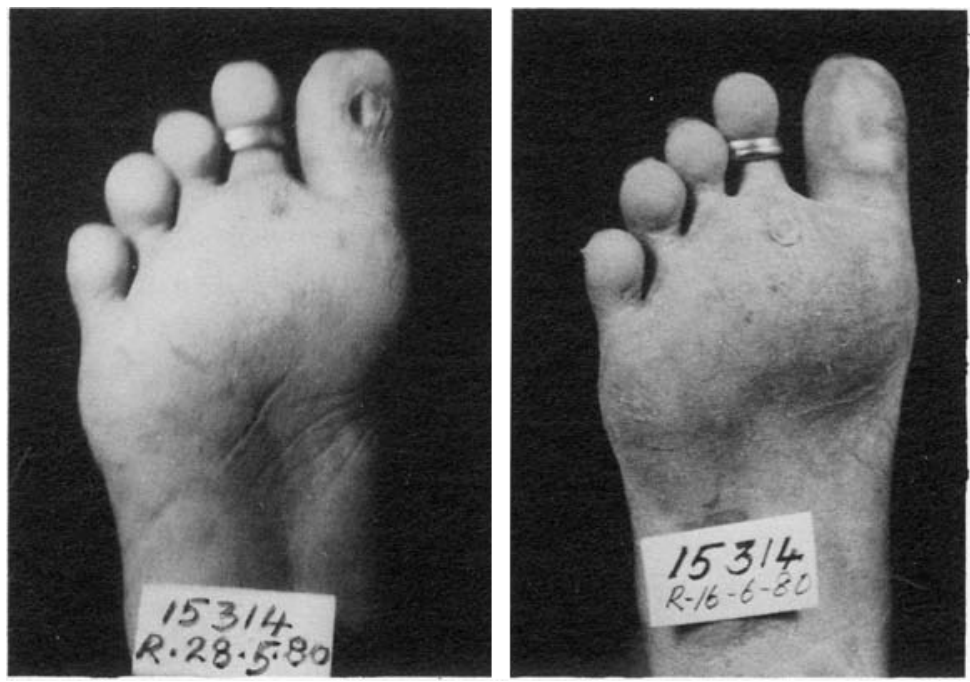

Figure 3. A Pre- and post-treatment foot showing the healing of an ulcer in 4 weeks.

Table 1. A comparison of the trial and control groups.

\begin{tabular}{lcc}
\hline & $\begin{array}{c}\text { MDRP shoe } \\
\text { group }\end{array}$ & $\begin{array}{c}\text { Control } \\
\text { group }\end{array}$ \\
\hline Patients & 21 & 21 \\
Ulcers & 26 & 24 \\
Age & & \\
$\quad 20-40$ & 10 & 13 \\
$\quad 41-60$ & 6 & 7 \\
$\quad$ Over 61 & 5 & 1 \\
Sex & & \\
$\quad$ Male & 16 & 16 \\
$\quad$ Female & 5 & 5 \\
Classification & & \\
$\quad$ N & - & 1 \\
$\quad$ N? & 9 & 7 \\
$\quad$ L & 12 & \\
\hline
\end{tabular}


Table 2. Sites and initial size of ulcers

\begin{tabular}{lcc}
\hline & $\begin{array}{c}\text { MDRP shoe } \\
\text { group }\end{array}$ & $\begin{array}{c}\text { Control } \\
\text { group }\end{array}$ \\
\hline No. of ulcers & 26 & 24 \\
Site & & \\
$\quad$ Base great toe & 6 & 6 \\
$\quad$ Forefoot & 19 & 18 \\
Lat. border & 1 & - \\
$\quad$ Heel & - & - \\
Size diameter $(\mathrm{cm})$ & 5 & 5 \\
$\quad$ Less than 1 & 17 & 16 \\
$\quad$ 1-3 & 4 & 3 \\
$\quad$ More than 3 & & \\
\hline
\end{tabular}

Table 3. Follow up at the first visit -4 weeks after joining the trial

\begin{tabular}{lcc}
\hline & $\begin{array}{c}\text { MDRP shoe } \\
\text { group }\end{array}$ & $\begin{array}{c}\text { Control } \\
\text { group }\end{array}$ \\
\hline Healed & $17(65 \%)$ & $3(12.5 \%)$ \\
Not healed & 9 & 21 \\
Total & 26 & 24 \\
\hline
\end{tabular}

\section{Complications}

The complications that we were specifically looking for were those which are commonly associated with any treatment involving the risk of osteoporosis resulting from plaster immobilization. ${ }^{3}$ In our small series this was not seen at all. Also at subsequent visits no case of neuropathic disorganization of the foot was seen. It is possible that the limited immobilization of the foot, below the ankle only, makes this risk negligible compared with the plaster boot.

In the initial experiments there were a few cases which produced ulceration around the open end of the shoe at the ankle. It also happened that some of the patients were able to remove their shoe by just slipping it off! However, with experience, both these difficulties were overcome.

\section{Discussion}

Effectiveness. It is clear from the results that the MDRP shoe is an effective form of treatment even after a minimum period of 4 weeks.

It embodies the three accepted principles of rigidity, ${ }^{4,5}$ immobilization of skin and bones below the ankle, and occlusion. 
Social acceptability. The shoe was very well accepted by the patient; in fact, some patients reporting at the Outpatient Department specifically requested the MDRP shoe.

Cost. The cost of a single MDRP shoe is about Rs $5 /-(25 p$ or $\$ 0.70)$ using home-made POP bandages.

The cost of dressings is very difficult to estimate as it depends on the standard of dressings used. Moreover, the ineffectiveness of dressings, even when supplemented by chappals with an arch support and metatarsal bar is demonstrated.

The cost of a standard below-knee POP boot with a Bohler iron is about Rs $25 /-(£ 1.25$ or $\$ 3.50)$ using home-made bandages.

\section{Conclusion}

The Moulded Double Rocker Plaster Shoe offers a very feasible method of treatment of the simple plantar ulcer under field conditions. It is effective, inexpensive, socially acceptable and the patient can be sent home on the day of application. There are no significant complications which have been noted either during or subsequent to this trial.

\section{References}

1 Fritschi EP. Care of feet. In: Thangaraj RH, ed. A Manual of Leprosy. New Delhi: The Leprosy Mission, 1980: 167.

2 Brand PW. Insensitive feet. 2nd edn. London: The Leprosy Mission, 1977: 56.

3 Fritschi EP. Reconstructive surgery in leprosy. Bristol: John Wright \& Sons Ltd. 1971: 167.

4 Bauman JH, Brand PW. Measurement of pressure between foot and shoe. Lancet 1963; i: 629 .

5 Bauman JH, Girling JP, Brand PW. Plantar pressures and trophic ulceration - an evaluation of footwear. J Bone Jt Surg 1963; 45B: 653. 